\title{
Remanufacturing in the Heavy Vehicle Industry-Case Study of a Finnish Machine Manufacturer
}

\author{
Pasi Rönkkö*(D), Sayed Mohammad Ayati $\mathbb{D}$ and Jukka Majava $\mathbb{D}$ \\ Department of Industrial Engineering and Management, University of Oulu, P.O. Box 4610, 90014 Oulu, Finland; \\ sayed.ayati@oulu.fi (S.M.A.); jukka.majava@oulu.fi (J.M.) \\ * Correspondence: pasi.ronkko@oulu.fi
}

\begin{abstract}
This study analyses remanufacturing operations of a Finnish heavy vehicle manufacturer with global operations. The company has remanufactured and refurbished certain components for a decade in a centralised remanufacturing and recycling centre in Finland, but it has encountered significant challenges, especially in reverse logistics. The company considers regional remanufacturing to decrease these disadvantages. The purpose of this study is to analyse the characteristics, challenges and benefits of regional remanufacturing by reviewing the relevant literature and analysing the empirical data, including a survey for international subsidiaries of the case company to determine regional needs. As a result, we have identified significant benefits, especially related to minimised logistics costs and better availability of the components, but also challenges, such as lack of resources, and insufficient economies of scale.
\end{abstract}

Keywords: circular economy; heavy vehicle industry; remanufacturing; refurbishing

Citation: Rönkkö, P.; Ayati, S.M.; Majava, J. Remanufacturing in the Heavy Vehicle Industry—Case Study of a Finnish Machine Manufacturer. Sustainability 2021, 13, 11120. https:// doi.org/10.3390/su131911120

Academic Editor: Barbara Aquilani

Received: 9 August 2021

Accepted: 5 October 2021

Published: 8 October 2021

Publisher's Note: MDPI stays neutral with regard to jurisdictional claims in published maps and institutional affiliations.

Copyright: (c) 2021 by the authors. Licensee MDPI, Basel, Switzerland. This article is an open access article distributed under the terms and conditions of the Creative Commons Attribution (CC BY) license (https:// creativecommons.org/licenses/by/ $4.0 /)$.

\section{Introduction}

The circular economy has increased in popularity in many industrial areas in recent decades because of its economic and environmental benefits, as well as due to diminishing natural resources [1,2]. According to King et al. [3] and Linder and Williander [1], in the circular economy, and especially in remanufacturing which is one of its main activities, up to $80 \%$ savings in materials and energy can be achieved. The heavy vehicle industry is not an exception because in this sector, $30-50 \%$ of savings have been achieved through remanufacturing $[4,5]$. However, the circular economy needs to be considered as early as in the life-cycle planning of the product $[4,6]$, and a poorly designed circular economy system may be even less sustainable than a well-designed linear economy system [6]. According to Frishammar and Parida [7], the shift to the circular economy may be slow and even take 1-3 years. One key consideration in the circular economy, and especially in remanufacturing, is the role of global versus local operations, i.e., the choice between centralized and decentralized production.

In this article, component remanufacturing and refurbishing operations in the heavy vehicle industry are studied. According to Saidani et al. [4], remanufacturing in the heavy vehicle industry is less mature and homogenous than the automotive industry. In addition, there are possibilities to recover large values because the components may be special and manufactured only in small batches. More precisely, the purpose of this study is to analyse the characteristics and challenges of remanufacturing in the heavy vehicle industry, and what benefits can be gained through decentralized remanufacturing. The case company of this study has had a centralised component and spare part remanufacturing for several years, but decentralised remanufacturing is currently studied to mitigate current challenges, such as logistics costs and long lead times. Some earlier studies relating to remanufacturing and end of life (EoL) management (i.e., actions to enable reducing environmental impacts and optimising the product life-cycle [5]) in the vehicle industry include comparisons of EoL management of light and heavy vehicles between the U.S. and the European Union [8], 
the influences of the EoL regulation on vehicle material circularity [9], and the impact of remanufacturing on the reduction in metal losses through the life-cycles of vehicle engines [10]. However, there are still few studies concerning remanufacturing in the heavy vehicle industry. For example, Saidani et al. have written papers regarding the adoption of the circular economy in the heavy vehicle industry $[4,8,11]$. In addition, Caterpillar is a large international manufacturer of heavy vehicles that has extensive experience in remanufacturing different components [4]. This company performs remanufacturing in eight different countries, which is close to the explored decentralised remanufacturing model of this study [12]. However, in this article, the case study is a medium-sized company with highly specialised, narrow product segments. This study indicates the challenges of a medium-sized company and determines the unique characteristics of remanufacturing operations with a focused offering. The above-described aims are condensed into the following research questions:

RQ 1. What are the unique characteristics and the key challenges of remanufacturing in the heavy vehicle industry?

RQ 2. What benefits can be gained through regional remanufacturing in this industry?

In this study, the research questions are addressed in a qualitative manner through both a literature review and an analysis of the empirical data. Section 2 includes the literature background and covers the circular economy in the vehicle industry and remanufacturing in general. The research methods are described in Section 3, and the results of the empirical data analysis are presented in Section 4. In Section 5, the results are discussed and compared with the findings reported in the literature. In Section 6, the conclusions are drawn, including the evaluation of reliability and validity, the study's implications and limitations, as well as suggested topics for further research.

\section{Literature Background}

\subsection{Circular Economy and Remanufacturing}

The circular economy has increased in popularity in recent decades, even though most companies still rely on the linear "take-make-use" system, where the products are considered waste at the end of their life-cycle [2,13]. Although the circular economy has no single clear definition [14], the basic idea behind it is the sustainability achieved, for instance, by utilising materials as effectively as possible, saving resources and energy [15], and closing the loops [3,6], thus keeping the materials in use as long as possible [9]. Besides environmental issues, the circular economy has been regarded as an economically feasible solution [13], offering many other advantages, such as increased local employment $[4,8,13,16,17]$, more sustainable economic growth, and increased security of supply and self-sufficiency [14,15]. However, Bocken et al. [6] states that a poorly designed circular economy system may be even worse than a well-designed linear economy system. Thus, circularity should be considered early in the planning of the product life-cycle.

EoL management refers to the actions related to a product that reaches at the end of life (EoL product) to enable reducing environmental impacts and optimising the product life-cycle [5]. Probably the most common EoL operations connected to the circular economy are reusing, repairing, refurbishing, remanufacturing and recycling $[5,13]$. In reusing, the products are used again as such, which requires the least resources and energy, whereas in recycling, the amounts of required energy and resources are much higher, and the original product's identity and functionality are lost [5,10]. According to Thierry et al. [5], the difference between refurbishing and remanufacturing is that in refurbishing, the used products are restored to a specified quality, usually less rigorous than new products, by fixing or replacing the most critical parts, or replacing outdated modules with technologically better ones to extend the products' service life. In contrast, remanufacturing means upgrading used products to a quality that is as good as new by replacing all worn-out or outdated parts. The purpose of repairing is to return used products to working order by fixing or replacing broken parts, but these products' quality is not as good as new. 
All the mentioned actions upgrade used products in terms of quality or technology, but their degrees of upgrading vary; repairing involves the lowest degree and remanufacturing involves the highest. Refurbishing, repairing and reusing lengthen the first life-cycle of the original product, whereas remanufacturing may enable further cycles of the products. Thierry et al. [5] use the term cannibalisation, which in this context means that only some reusable parts or components of the main product are used (e.g., in repairing, refurbishing or remanufacturing). However, the different operations are not separate. For example, components that are not useful for remanufacturing may be suitable for cannibalisation, and parts rejected for cannibalisation may be suitable for recycling.

King et al. [3] (p.257) mention that remanufacturing may be one of the best strategies in the circular economy because "it enables the embodied energy of virgin production to be maintained, preserves the intrinsic 'added value' of the product for the manufacturer and enables the resultant products to be sold 'as new' with updated features if necessary". King et al. [3] also state that repairing is the most logical option to extend a product's life, but it is not as good an option as remanufacturing or reconditioning in terms of quality.

\subsection{Remanufacturing Benefits, Barriers and Drivers}

Remanufacturing is considered a circular economy process to restore used products to a like-new condition and thus extend their useful lives [8,18]. It is widely performed for military products and components, commercial transportation-related products and equipment, commercial heavy equipment and other commercial applications [5]. Because the products are restored almost as new, their quality is usually guaranteed, with a warranty similar to that of new products $[3,18]$. However, remanufacturing usually requires the greatest degree of work to enable superior quality and reliability compared with other circular economy activities [3]. Soo et al. [9] suggest remanufacturing in the vehicle industry as the most useful method for parts that are not vulnerable to wear and tear, whereas King et al. [3] mention that it is most applicable for complex electro-mechanical and mechanical products with cores that will have added value. As a concept close to remanufacturing, reconditioning or refurbishing entails rebuilding or replacing the major components to enable product functionality, thus requiring less resources than remanufacturing. However, the product is not considered new, and it does not offer the latest functionalities or precise styling [3].

The commonly recognised phases of the remanufacturing process are core collection, product disassembly, cleaning, inspection, restoration, storage of the parts, replacement of the components and reassembly of the product $[3,8,19]$. Inspection is a critical phase of selecting suitable parts for remanufacturing; otherwise, the appropriate parts might be downgraded or recycled.

\subsubsection{Benefits of Remanufacturing}

Remanufacturing brings environmental and economic benefits, which are connected to reduce virgin material consumptions, energy, carbon dioxide emissions and wasted materials [8]. As a vital strategy in remanufacturing, waste management benefits manufacturers by saving costs and earning higher profit margins for them, which can also be advantageous for customers in terms of reduced environmental impacts and lower costs for remanufactured products $[5,8,18]$. As a result of remanufacturing, up to $85 \%$ of the weight of remanufactured products can be retained [18]; simultaneously, they require $50-80 \%$ less energy to produce [1,18], resulting in up to $80 \%$ savings in production costs [18]. Thierry et al. [5] state that some products may also be upgraded to new quality items with 50-60\% cost compared with new products, even beyond the specifications of the original products. Although remanufacturing involves more work than repairing and reconditioning, the quality can be seen as good as new $[8,18]$. According to Ijomah et al. [18], raw material production and shaping and machining processes generate the highest carbon dioxide emissions, which are omitted by remanufacturing. By buying the products back, the manufacturers may gain many advantages, such as inexpensive sources of valuable materials 
and components, which can be used for service or manufacturing purposes, and it may also provide an opportunity to sell or lease new products [5]. Thierry et al. [5] have also observed that companies leasing their products are generally in a more favourable position than those that sell their products.

\subsubsection{Challenges of and Barriers to Remanufacturing}

The recognised challenges related to remanufacturing are presented in Table 1.

Table 1. Challenges of remanufacturing.

\begin{tabular}{cc}
\hline Challenge(s) & Author(s) \\
\hline $\begin{array}{c}\text { Challenging materials, increased product complexity, } \\
\text { unsuitability for remanufacturing }\end{array}$ & {$[3,4,6,10,11,18]$} \\
\hline $\begin{array}{c}\text { Material collection, reverse logistics, lead time and core } \\
\text { management }\end{array}$ & {$[8,10,19]$} \\
\hline Uncertain and varying quality of the returned cores & {$[8,10,19]$} \\
\hline $\begin{array}{c}\text { Shortage of skilled workforce and lack of } \\
\text { remanufacturing-specific tools and techniques }\end{array}$ & {$[4,8,18]$} \\
\hline Additional resources and costs of remanufacturing & {$[4,8,18]$} \\
\hline Lack of stable demand & {$[3,18]$} \\
\hline Unpredictability and low reliability of capacity planning & {$[1,19]$} \\
\hline Lack of clear legal definitions and standards & {$[10,18]$} \\
\hline $\begin{array}{c}\text { Legislation, such as restrictions on importing cores and } \\
\text { remanufactured goods, and environmental legislation }\end{array}$ & {$[10,18]$} \\
\hline $\begin{array}{c}\text { Marketing of remanufactured products and finding markets } \\
\text { (increasing prosperity, throwaway culture, customer demand for } \\
\text { newness, valuing newness more than quality, and technological } \\
\text { advances of new products) }\end{array}$ & {$[5,18,19]$} \\
\hline Intellectual Property Rights (IPR) restrictions & {$[18,20]$} \\
\hline Pricing models & {$[8]$} \\
\hline
\end{tabular}

Many authors $[4,9,11]$ recognised, especially regarding the vehicle industry, that while the manufacturers aim to reduce the weights of the vehicles by using material mixtures such as carbon fibre-reinforced plastics, the vehicles become less recyclable, and the EoL operations become more expensive over the years. Saidani et al. [4] mention some challenges related to new technologies, such as the Internet of Things (IoT), which connects devices with a large number of electrical components, or hybrid vehicles with lithiumion batteries. According to Zhang et al. [10], the quality of some remanufactured parts (e.g., metal parts) may not be as reliable as new ones, which complicates the operational planning of the remanufacturing [19]. Marketing remanufactured parts may also pose a challenge. Although they can be considered new, the products contain used parts, components and materials [19]. According to Thierry et al. [5], the end-user acceptance depends on differences in quality and costs between used and new products. Hartwell \& Marco [20] state that the companies may have ambiguous ideas on how to manage intellectual property rights (IPR) related to remanufacturing.

Remanufacturing may require redesigning the products for easier recovery at their EoL, which is not self-evident because the products may have been designed for easy assembly, manufacturing, recycling or minimising distribution costs, which may make the disassembly needed for remanufacturing a challenge [3,5,18]. Disassembly is one of the main remanufacturing activities; poor disassembly ability may prevent access for rectification and cleaning activities [18]. According to Saavedra et al. [19], most manufacturers select their suppliers based on low prices, resulting in lower priced products, 
which in turn may lead to worse remanufacturing conditions. Thierry et al. [5] add that cost minimisation through less re-manufacturable products is justified if customers are not ready to pay for green products. However, by offering green products, companies may attract environmentally conscious customers and employees. Ijomah et al. [18] also mention that manufacturers may prevent remanufacturability to maintain sales of new products. According to Frishammar and Parida [7], it may not be easy for companies to adopt circular economy models because they have to change the ways that they create, deliver and capture value, and business models may be difficult to change from linear to circular if the steps are poorly understood or there are no legislative incentives [1].

Logistics is considered one of the most important yet one of the most challenging issues in the circular economy. Many applications require moving or collecting the materials, and usually, circular economy solutions require take-back models to return the products to the manufacturer [21]. Additionally, economic quantities are sometimes prerequisites for effective take-back models. King et al. [3] mention reverse logistics as a barrier to remanufacturing because it usually requires returning EoL products from a small number of locations, which may be the highest cost involved in remanufacturing. Leppänen et al. [22] have also concluded that narrow material streams in a sparsely populated region may be a combination that makes the system inefficient. Hummels et al. [23] support this view, adding that operations in several geographic locations may be unprofitable in case of excessive tariffs and logistics costs. Stål and Corvellec [21] recognise an issue called imbalance in return logistics, which means that the returned goods do not go back to the original product manufacturer. Original equipment manufacturers (OEMs) also have their role in taking back the products in some industrial sectors, and sometimes they are forced by laws and regulations to take the products back from the customers [24].

\subsubsection{Drivers of Remanufacturing}

According to Thierry et al. [5], remanufacturing may have large influences on production, operations and logistics management, and it may need strategic changes to deal with remanufacturing. Thierry et al. [5] propose that the benefits of remanufacturing are greatest when the flows of returned products are predictable. Active vendor-customer relations and retained ownership of the products, such as offering products as services in the form of leasing or renting, are drivers for overcoming the volatile return flow of products in remanufacturing [1,5,7]. King et al. [3] suggest various methods to motivate customers towards remanufacturing, such as providing discounts for new products, offering free postal returns and voluntary sector partnerships with retail groups.

According to Saavedra et al. [19], remanufacturing can be performed by different actors in the supply chain, such as the original equipment manufacturer or a third-party provider. However, by taking the products back at the end of their service lives, the original manufacturers may keep the EoL operations in their own hands, thus preventing unauthorised EoL operations and allowing them to control the quality of remanufactured products [18]. According to Linder \& Williander [1], a collaborative partner network may also be an advantage if the material recovery is differentiated.

Remanufacturing should be considered as early as in product planning to enable efficient remanufacturing operations, which include ease of identification, access, handling and durability [18]. Easier access enables more efficient cleaning, rectifying faults, inspecting and testing. It is also important to use components that can be remanufactured with less effort, without using hybrid components that are not easily separable, and to use attachment methods that are suitable for remanufacturing. Ijomah et al. [18] also mention that it is important that re-manufacturability does not affect the aesthetic appearance of the product.

The identified success factors for remanufacturing are usually related to costs and environmental impacts, such as the price ratio between new and remanufactured products, the buy-back cost of used products compared with the cost of new products, the energy used for remanufacturing compared with making new products, and the mass of recovered 
components compared with that of the new product [5,8]. Chopra and Sodhi [25] suggest that to be economically feasible, production should be planned so that the capacity is sufficient for effective production. However, excessive capacity may hurt operations financially, and one solution to mitigate excessive capacity is flexibility so that the capacity can be used for many types of products. Chopra and Sodhi [25] also mention that economies of scale can be achieved by serving geographically scattered customers from centralised plants. Stål and Corvellec [21] suggest building a suitable infrastructure, including finding and scaling up suitable technologies and determining how to transport collected goods back to producers.

Thierry et al. [5] assert the importance of examining which organisations are involved in remanufacturing and which obstacles may occur in the entire process. According to Linder and Williander [1], the requirements for efficient remanufacturing include the following:

- The core can be used in the restored product.

- The components fail functionally rather than by dissipation.

- The value added to the remanufactured component is relatively high compared with the market value and the original cost.

- The components are factory built rather than assembled.

- The processes and the product technologies are both stable.

Thierry et al. [5] state that when changing production strategies to be more circular, both forward and return logistics should be considered, and warehouses should be designed to deal with two-way movements of the products. It is also important to deal with uncertainties in quantities, timing and quality of used products in remanufacturing. Additionally, customers should be convinced that reprocessed products fulfil all their quality requirements.

\subsection{Remanufacturing in the Automotive and the Heavy Vehicle Industries}

Automotive part remanufacturing is the most prominent area of remanufacturing. It has been estimated that in the automotive industry, remanufactured gasoline engines can be produced with significantly less raw materials compared with the production of new engines $[9,10]$. Because car manufacturers are significant users of steel and aluminium, there is constantly increasing pressure to optimise the use of recycled materials to ensure continuous raw material supply [9]. Karagoz et al. [26] find that recycling EoL vehicles is not only an environmental issue, but it may also be regarded as a financial source for the vehicle industry and associated industries. The number of remanufactured components in the passenger car industry may be relatively high. According to the Ellen McArthur Foundation [17] and Saidani et al. [4], Renault has remanufactured roughly 200,000 components.

According to Saidani et al. [11], there are similarities and differences in remanufacturing in the automotive and the heavy vehicle industries; the components and materials are basically the same, but there are differences in regulations and marketing practices. Remanufacturing in the heavy vehicle industry is also less developed than in the automotive industry $[4,8]$. However, manufacturers in the heavy vehicle industry are increasingly recognising the potential of circular economy practices to increase the value of their products and materials and to mitigate the risks associated with volatile material prices and supply. According to Saidani et al. [4], remanufacturing in the heavy vehicle industry may be highly heterogeneous, but components such as tires and alternators are suitable for remanufacturing. In the heavy vehicle industry, the economic benefits are huge because the components may be special and manufactured only in small batches; thus, economies of scale are not fully achieved in manufacturing [4]. Remanufacturing in the heavy vehicle industry should be supported by suitable expertise, methods and tools, and EoL vehicle recovery requires its own supply chain management [10]. Saidani et al. [4] suggest that remanufacturing should be done in the region where the vehicles are used in order to be economically viable. 


\section{Materials and Methods}

This study is qualitative in nature and a case study method is employed to reach the research aims. The selected case is a medium-sized manufacturer of highly specialised heavy vehicles with approximately 1000 employees and revenue of 500 million $€$. The main factory is located in Finland, and the company has subsidiaries in several countries, such as in Brazil, Uruguay, USA, Russia, and China. It is one of the leading companies in its sector and therefore it was deemed to represent the industry under study well. In addition, the company has conducted remanufacturing for several years and it is now considering also regional remanufacturing, which matches the focus of this study. According to Yin [27], a case study is a suitable method when investigating contemporary phenomena and the results cannot be affected by the researcher. This study includes a literature review and an analysis of empirical data. The reviewed literature consists of peer-reviewed articles related to the circular economy and remanufacturing in general, as well as those related to remanufacturing in the automotive and the heavy vehicle industries. The first searches were conducted in the Scopus article database by using the keywords "vehicle" AND "remanufacturing", and "heavy" AND "vehicle" AND "remanufacturing", which generated sufficient search results. More general articles related to the circular economy and remanufacturing, which were found from the aforementioned articles (snowball sampling method) or by using the keywords "circular economy" and "remanufacturing". The article titles and abstract were screened and the most relevant articles (published between 1995 and 2021) within the study scope were included for further reading and analysis to create the literature background of the study.

The empirical data collected in the case study include meeting notes, company documentation and a survey. Access to the data was achieved through the research project collaboration with the case company and the data was collected between March and June 2021. The survey was administered to five subsidiaries by using a semi-structured questionnaire (Appendix A), which was sent through Webropol tool. The survey included open and yes/no questions, and the respondents were instructed to answer the questions with their best available information. In some yes/no questions, it was possible to provide additional information. To determine the state of remanufacturing and the willingness to remanufacture certain components and machine types, the answers were given by using a multi-choice matrix. The survey respondents included a supply chain manager, an after sales manager, a service manager, a parts manager, and a spare parts and logistics manager. The survey was created to obtain answers to questions related to the current state of remanufacturing and the needs and requirements for decentralized remanufacturing. Some examples are as follows: are there already remanufacturing or other EoL services in the region performed by the subsidiary itself or a third-party stakeholder? Are the customers willing to pay for these services? What are the qualifications for remanufacturing? Are there recognised challenges related to remanufacturing? Basically, through this survey, we wanted to determine which components would be best for remanufacturing in which regions and whether there were any regional differences needed to start successful remanufacturing. At the end of the study, the analysis of the survey results was compared with the findings from the literature review to discuss the findings and to draw conclusions. Figure 1 illustrates the different phases of the research process.

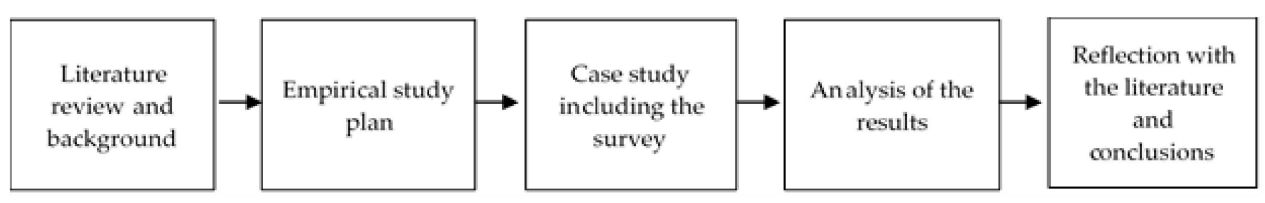

Figure 1. Research process. 


\section{Results}

\subsection{Case Description}

The case company is a Finnish manufacturer of special heavy vehicles, with worldwide markets, narrow product segments and a low annual quantity of sold machines. It is one of the leading manufacturers in its sector. The company's main factory is located in Finland, where all the machines are assembled. The company also has regional subsidiaries worldwide, providing maintenance and support services.

The case study is already performing three recovery approaches, (1) refurbishing, (2) remanufacturing, and (3) recycling. The quality control engineering department defined a method to assess the quality of the EoL products into various categories. To assess the current quality, the workforce disassembles the EoL products into critical components based on transmission use, (1) differential and planetary gear, (2) transfer boxes and axles, (3) engines, and (4) hydraulic parts. These parts are required to meet the minimum level of quality to adopt reconditioning and remanufacturing. In the reconditioning centre, the company produces ready-made assemblies and packages which enable fast repairs and maintenance. These packages reduce the cost of the individual part by $10-15 \%$. The remanufacturing centre is where the company requalifies EoL critical components. Remanufactured components are like-new in terms of quality, and they are $30 \%$ cheaper for customers than new products. The remanufacturing centre employs four mechanics and a team leader to remanufacture and assemble products. The process steps are divided among the mechanics by product groups, and product-specific expertise is utilised to control the process. The recycling centre recovers the material values of components with insufficient quality level. This centre employs a team leader and two specialists. The company realized a stable flow of components enables steady workloads and availability of components. The EoL processes depend on the product and reaching a stable flow. By investigating the centralized remanufacturing centre versus several geographic locations (decentralized operations), it can be understood what challenges the case company faces from the perspective of three tiers of sustainability. In the centralized model, the significant challenge of the company is the economic point of view. Taking back EoL products from the customers to the OEM is limited due to long distances. This challenge includes reverse logistics cost, fiscal issues, and customs fees. In addition, from the environmental viewpoint, the long transportation distance increases $\mathrm{CO} 2$ emissions.

\subsection{Problem Description}

For several years now, the company has had centralised refurbishing, remanufacturing and recycling operations for components located close to its main factory in Finland, but there have been significant challenges, especially related to reverse logistics such as customs fees and delays, as well as transportation costs. If remanufactured components are used to replace new products through the current remanufacturing system, the components cannot meet customer needs in terms of lead time. According to the principles of the circular economy, the case company aims to study a shift from a centralised to a decentralized remanufacturing model so that there would be regional remanufacturing centres dispersed among several geographic locations. Decentralized remanufacturing has advantages and disadvantages. Emissions and logistics costs may be lower, but economies of scale may not be achieved in remanufacturing because the material flow of the cores is smaller in the decentralised model compared to the centralised model. Taking back and recovering values of the EoL products from long distances are challenges from the perspective of economics and environmental goals. The greatest challenges in centralised remanufacturing are related to reverse logistics once taking back the products from the customers to the OEM, especially via longer distances. The limitations include the logistics cost, fiscal issues, and customs fees. For some regional subsidiaries taking back EoL components from a long distance is not cost-effective. The two significant issues that case study showcases are (1) the absence of quality assessment at the collecting point and (2) produced CO2 
emissions. The company has also found that the quality of the components may not meet the minimum required level for remanufacturing.

\subsection{Decentralization of Remanufacturing}

To cope with the abovementioned challenges related to reverse logistics, the case company aims to study a shift from a centralised model to a dispersed regional model of remanufacturing. In other words, each regional subsidiary will have its own remanufacturing service. According to the survey, some remanufacturing is already being carried out in each region, and there is clear willingness for that service. The respondents saw that in this type of industry, spare parts should be available as fast as possible because machine breakdowns during work times will cause immediate loss of profits if substitute machines or components are unavailable. Thus, replacement components or parts should always be in stock, and remanufacturing can be regarded as a good option to ensure a secure supply because the cores for remanufacturing already exist in each region. Repair kits, including the needed parts, were also perceived as good options to repair the broken components in a region without sending them back to Finland. However, most respondents viewed remanufactured parts as better options than repair kits, which justifies developing regional remanufacturing services.

The results show some locations do not have equipment to remanufacture some parts because of their sizes and lack of sufficient lifting capacity. According to the survey, the needs for remanufacturing vary, depending on the region and its typical customer segments. For example, in one country, the most common groups of machine users are small entrepreneurs with small and variable fleets, whereas in another country, the most common customers are large entrepreneurs with large fleets, including only a few machine types.

In general, remanufacturing was considered a challenge among the respondents because it requires special tools, knowledge and other resources. It is also recognised that remanufacturing some components is not economically feasible if the parts needed for remanufacturing are so expensive that the remanufactured component becomes more expensive than a new one. Some regions encounter the challenge of the customers' unwillingness to use remanufactured components, except when new parts are unavailable. Yet, the key challenge was considered to be managing the flow of the cores, basically, returning the cores from the customers for remanufacturing. In the current system where the remanufacturing is centralised in Finland, the logistics costs, fiscal issues and toll fees form a significant addition to the prices of the cores. For some regions, returning the cores to Finland is not even an option. Another identified challenge related to core management is competition in remanufacturing services. In many regions, there are third-party providers of remanufacturing, which have decreased return flows for the case company and its subsidiaries. Additionally, some respondents saw that if the remanufacturing is done by unauthorised parties, the quality cannot always be guaranteed. Remanufacturing was also regarded as a business opportunity that can potentially increase the revenue.

Based on the results, the remanufactured components are not preferred in some regions, but usually they are regarded as good options if they are available, and their prices are affordable. Sometimes, remanufactured parts are preferred over new parts if their prices are much lower than those of the new ones. Second-hand markets for used components were also found to be common and they are considered huge opportunities for most regions.

For the challenges related to return logistics, one already used and well-recognised solution is the deposit system, which means that the price of a component includes a deposit fee, which is returned if the component is returned to the manufacturer. However, the survey results show that the deposit system is not widely used, and its uses vary a lot. In some regions, it is included only in some "full services".

If the processes can be performed by third-party providers with already existing equipment, the processes may be more efficient. Some parts used in the machines are manufactured by other parties and are thus more standardised. To predict the core flows, 
one studied solution in the survey was predictive maintenance by using intelligent systems to monitor components in real time. If there are indications that the components will break down, they are replaced in advance. However, this system would require additional fees charged to customers, and according to the survey, the willingness to pay more may depend on the customer segments if the cost is not built into the price of the machine.

\section{Discussion}

The case company gains several benefits through remanufacturing, especially in cost reduction, in line with the results obtained by [1]. Remanufactured spare parts are sold with roughly $30 \%$ lower prices than those of new parts, which is a common finding reported in the literature $[1,4,5]$. As found in this research, Refs. [5,19] have also recognised that the acceptance of the remanufactured parts varies even though their quality is considered even better than that of new products, and the main reason for preferring remanufactured parts may be their lower prices.

However, the company has encountered challenges related to reverse logistics, including freight costs, custom fees, delays and fiscal issues, as recognised also by $[8,10,18]$. Collecting the cores from customers is also difficult, which is in line with the findings of $[1,22]$. The deposit system has been seen as a solution to prevent unauthorised remanufacturing and return the cores more efficiently from the customers. Nonetheless, although third-party remanufacturing is perceived mostly as a threat, it can also be regarded as a benefit. Implementing and developing remanufacturing processes may need large investments that may have long pay-back times, and sometimes, third-party remanufacturers are better equipped for certain processes. Other options to boost core collection from the customers to OEMs could be laws and regulations to take the used products back, as used in some industrial sectors [24]. However, this was not a challenge in this case since the case company had willingness to take the products back for remanufacturing. Saidani et al. [4] have recognised that the vehicles should be remanufactured in the region where they are used in order to be viable. Regional and dispersed remanufacturing have both positive and negative effects. On one hand, emissions and logistics costs may be lower; on the other hand, economies of scale may not be achieved, partly because the material flows may not be stable.

Remanufacturing of every part type may require unique processes, expertise and tools; remanufacturing of all parts may be unprofitable. For successful remanufacturing, special tools, knowledge, headcount, facilities and other resources are needed. The lack of abovementioned issues brings obstacles to remanufacturing performances. To achieve the economies of scale, the focus should be on higher volume components. However, the lack of a needed component in the case of a machine breakdown may be expensive; in the studied case local remanufacturing was seen as a way to increase the availability of urgently needed components, which is a significant, rarely mentioned finding in the context of remanufacturing. Another novel finding is related to the resources and knowledge challenge. In the studied case this challenge was addressed by using the "master and the journeyman" method, which means that the employees from different regions are sent to Finland and trained by experienced remanufacturers. This allows similar expertise for every region and the possibility to enable the guaranteed quality of the remanufactured products. However, every machine type and model consist of some unique components and parts, and if new components start to be remanufactured, additional training is usually required. The case company's products are quite unique and highly specialised, with roughly just 1,000 machines sold per year worldwide. The models of the manufacturer have varied due to constant product development and evolution over time. For dispersed remanufacturing, the number of regionally remanufactured components may be low, and it is not necessarily cost-effective to reprocess all the components, since special tools, instructions and expertise may be needed for processing. Some common product parts are produced by other manufacturers; thus, they are more standardised. For the specialised components, the case company's own remanufacturing operations could provide better quality, whereas for the standardised components manufactured by others, collaborative networks may be 
beneficial. This option may enable economies of scale for both the third-party manufacturer and the case company, which may decrease remanufacturing prices. However, IPR-related issues may sometimes be an obstacle for third-party remanufacturing $[18,20]$. When the customers are more heterogeneous, with varying machine types, they also have needs for many types of components, but when there are large customers with only a few machine types, it is easier to maintain the selection of the spare parts.

Although Soo et al. [9] have recognised that in the vehicle industry, the highest circular economy potential would be in scrap utilisation because the technologies and the materials change, the change may not be as significant in highly specialised heavy machines. As Saidani et al. [4] have noted, the benefits of remanufacturing in the heavy vehicle industry may be substantial because of high specialisation and small production batches, which do not enable economies of scales in manufacturing. Thus, the value can be increased through remanufacturing.

Even though the case company focuses more on economic aspects of sustainability in remanufacturing, the environmental and social perspectives are important to consider too. In remanufacturing, it is possible to upgrade the components to follow current recommendations [5]; thus, it would be beneficial to manufacture long-lasting components that can be easily remanufactured and upgraded [18]. This should be taken into account in the design phase to consider all life-cycle phases [28]. As many authors have concluded [6,22], excessive generated emissions or excessive amounts of used energy in reverse logistics or other circular economy processes may reduce the environmental benefits of the circular economy systems. However, the value chain of manufacturing itself generates significant emissions and requires the use of energy in various phases; thus, it is easy to see why remanufacturing can be perceived as a green solution despite having various challenges. Regarding social aspects, decentralized remanufacturing increases local production and material flows, which in turn can provide new job opportunities locally.

\section{Conclusions}

In this study, we have examined the remanufacturing operations of a Finnish heavy vehicle manufacturer and its potential shift from a centralised to a dispersed remanufacturing model. While the reasons for this shift may be company-specific, the case provides an interesting example of the general aim towards more local material flows in the circular economy. The study is based on a literature review and empirical research, including a survey that was sent to regional subsidiaries of the case company. In the first research question, we have asked, "What are the unique characteristics and the key challenges of remanufacturing in the heavy vehicle industry?" When the remanufacturing operations are centralised as in the current case, some concrete challenges have been identified in the literature, as well as in this study. The logistics itself generates costs in the forms of transportation costs, toll fees and fiscal issues when crossing the borders of the countries. Long-distance transport of components that do not have value for remanufacturing can also be considered a waste of time and resources. When considering the green nature of the circular economy, emissions caused by logistics can be an issue, which may reduce the value of the whole concept. While regional operations decrease emissions and costs generated by logistics, economies of scale may not be achieved. When the variation of different machine types is high, this leads to the need for different tools that are required for remanufacturing component variations. Some components may be challenging to remanufacture, and some remanufactured components may be even more expensive than new parts, which make remanufacturing an economically unfeasible option.

In the second research question, we have asked, "What benefits can be gained through regional remanufacturing in this industry?" Because the products are highly specialised, with worldwide markets, and the manufacturing of the machines is highly centralised, by implementing regional remanufacturing, the components can be more available, while their prices may stay lower than those of the original parts. Constant remanufacturing in the region also increases the availability of the spare parts of discontinued model lines, 
thus ensuring the secure supply of these spare parts. In conclusion, remanufacturing may not only offer economic and environmental benefits but also make specialised parts more available.

In this study, we have found significant issues related to the circular economy of the heavy vehicle industry. The machines of the case company are highly specialised, and the total quantity that it produces annually is relatively low. The machine types in certain regions may vary, and besides the needs for certain components, the specific needs of each region should be evaluated. Although cost effectiveness may not be achieved, dispersed remanufacturing may bring other economic benefits and a secure supply if the components are available within a shorter timeframe, which may be vital for the companies using the machines. Otherwise, if their machines break down, their productive activities are disrupted, which may decrease their monetary flows.

Naturally, this study has limitations. It included only one case company, and the survey for the data collection was sent to the subsidiaries in five regions to evaluate their specific needs. The survey included both open and yes/no questions. The respondents were instructed to answer the questions with the best available information, but there may still be a lack of some issues that were mistakenly believed to be irrelevant. The expertise of the respondents may also vary, which may have affected the validity of some of their answers because a number of questions may have been misunderstood. The case study as a research method also causes some limitations because the results are hard to generalize, and they may only be valid for the case company. For further research, it would be beneficial to determine the most affordable components to be remanufactured and the total costs of remanufacturing. In addition, statistical analyses on the use of remanufacturing and part circulation flow in heavy vehicle industry in different regions and countries could be conducted.

Author Contributions: Conceptualization, P.R. and J.M.; methodology, P.R.; validation, P.R., S.M.A. and J.M.; investigation, P.R. and S.M.A.; writing-original draft preparation, P.R., S.M.A. and J.M.; writing - review and editing, P.R., S.M.A. and J.M.; supervision, J.M.; project administration, J.M.; funding acquisition, J.M. All authors have read and agreed to the published version of the manuscript.

Funding: This research received no external funding.

Institutional Review Board Statement: Not applicable.

Informed Consent Statement: Not applicable.

Data Availability Statement: The data is available upon request.

Acknowledgments: The authors thank the case company and all the stakeholders who participated in the survey. We also thank the reviewers who gave us professional suggestions to improve the paper.

Conflicts of Interest: The authors declare no conflict of interest.

\section{Appendix A}

*The identifiers are removed to avoid misuse of the information. The name of the company is replaced by "case company", and the different machine types are replaced by numbers with Models a-n.

Questions for the case company* network

This survey has been developed for the stakeholders of the case company network to determine the issues related to remanufacturing and its major challenges, such as cost, availability and reverse logistics. In this survey, we focus on the transmission components that are currently remanufactured in-house (e.g., differential gear, planetary gear, transfer box, hub). The answers will be used for developing the case company's service offerings, and some scientific articles can be written based on the survey. The answers will be handled with confidentiality, and all identifiers related to the stakeholders will be removed in the publications.

Remanufacturing of the components 
In this first section, we ask in detail which components should be remanufactured for which machines. Choose the component(s) most in demand for each machine. The needs for remanufacturing are related to the consumption of the components, their availability and the cost efficiency of remanufacturing them. The machines are listed below.

Machine type 1 (multiple-choice matrix)

- Model a

- Model b

- Model c

- Model d

- Model e

- Model f

- Model g

Machine type 2 (multiple-choice matrix)

- Model h

- Model i

- Model j

- Model k

- Model 1

- Model m

- Model n

- Overall, what components are the most in demand in the region and could best circulate?

Are there any clear connections between different machines and components? Can you give some examples? (e.g., Certain components of a certain machine type are consumed more often than others, etc.)

- Which components could be remanufactured or reconditioned at affordable costs?

- For which components could customer repair kits be the best option? (Repair kit = kit that contains the basic parts for repairing specific components)

- Which components could be the easiest to remanufacture? Why?

- Which components could be the most challenging to remanufacture? Why? (e.g., lack of tools, lack of information, etc.)

Needs for remanufacturing

- Are some specific tools needed for remanufacturing?

- Are there needs for specific instructions or extensive training of the personnel for remanufacturing?

- Are any specific needs or challenges related to core quality assessment?

- Do you recognise any other specific needs related to remanufacturing?

Reverse logistics of remanufacturing

- Briefly describe the structure of the remanufacturing logistics. How are the cores collected?

- Are any deposit systems included?

- Are the components circulating within the company? Are some components sold outside the company? (e.g., second-hand markets)

- Do you foresee that remanufactured components may cause cannibalisation in the region? (e.g., remanufactured components may significantly supersede new parts in sales)

- Do you observe the challenges in reverse logistics?

- If yes, what are the greatest challenges encountered in reverse logistics or in returning the cores to Finland?

Which things may add costs?

- Do you think that a local remanufacturing centre could be useful? 
Components, customers and life-cycles of the machines

- What remanufactured parts could be sourced locally?

Competition in remanufacturing

- Is there any competition in the remanufacturing services?

- If yes, do you perceive it as a threat or a challenge?

- Do you think that the core deposit system could ease the situation?

- Are there any third-party competitors that provide remanufactured parts for the machines of the case company?

- Do you foresee that there could be either competition or cooperation in this area? (e.g., a larger company specialising in remanufacturing certain components produced by multiple manufacturers)

- Do you see any reasons why the remanufacturing should be kept in the hands of the case company? (e.g., quality issues)

- If third-party remanufacturing is used, what are the reasons for choosing a third-party remanufacturer?

\section{Predictive maintenance}

- On average, how old are the machines in the region? Do the customers prefer newer or older machines? Is there some variation among customer segments?

What kinds of parts are needed for the machines in the region?

- Do you anticipate a need for predictive maintenance? For example, components are monitored and replaced if there are indications that they will break down.

- Do you foresee that this could serve the customers better, and would they be willing to pay more for this kind of service?

- Would there be variations in the need for this kind of service among different customer segments? Could one customer group benefit more than others from this kind of service?

\section{References}

1. Linder, M.; Williander, M. Circular Business Model Innovation: Inherent Uncertainties. Bus. Strateg. Environ. 2017, 26, 182-196. [CrossRef]

2. Patwa, N.; Sivarajah, U.; Seetharaman, A.; Sarkar, S.; Maiti, K.; Hingorani, K. Towards a Circular Economy: An Emerging Economies Context. J. Bus. Res. 2021, 122, 725-735. [CrossRef]

3. King, A.M.; Burgess, S.C.; Ijomah, W.; McMahon, C.A. Reducing Waste: Repair, Recondition, Remanufacture or Recycle? Sustain. Dev. 2006, 14, 257-267. [CrossRef]

4. Saidani, M.; Yannou, B.; Leroy, Y.; Cluzel, F. Heavy Vehicles on the Road towards the Circular Economy: Analysis and Comparison with the Automotive Industry. Resour. Conserv. Recycl. 2018, 135, 108-122. [CrossRef]

5. Thierry, M.; Salomon, M.; Van Nunen, J.; Van Wassenhove, L. Strategic Issues in Product Recovery Management. Calif. Manag. Rev. 1995, 37, 114-136. [CrossRef]

6. Bocken, N.M.P.; de Pauw, I.; Bakker, C.; van der Grinten, B. Product Design and Business Model Strategies for a Circular Economy. J. Ind. Prod. Eng. 2016, 33, 308-320. [CrossRef]

7. Frishammar, J.; Parida, V. Circular Business Model Transformation: A Roadmap for Incumbent Firms. Calif. Manag. Rev. 2018, 61, 5-29. [CrossRef]

8. Saidani, M.; Yannou, B.; Leroy, Y.; Cluzel, F. Dismantling, Remanufacturing and Recovering Heavy Vehicles in a Circular Economy-Technico-Economic and Organisational Lessons Learnt from an Industrial Pilot Study. Resour. Conserv. Recycl. 2020, 156, 104684. [CrossRef]

9. Soo, V.K.; Doolan, M.; Compston, P.; Duflou, J.R.; Peeters, J.; Umeda, Y. The Influence of End-of-Life Regulation on Vehicle Material Circularity: A Comparison of Europe, Japan, Australia and the US. Resour. Conserv. Recycl. 2021, 168, 105294. [CrossRef]

10. Zhang, Z.; Matsubae, K.; Nakajima, K. Impact of Remanufacturing on the Reduction of Metal Losses through the Life Cycles of Vehicle Engines. Resour. Conserv. Recycl. 2021, 170, 105614. [CrossRef]

11. Saidani, M.; Kendall, A.; Yannou, B.; Leroy, Y.; Cluzel, F. Management of the End-of-Life of Light and Heavy Vehicles in the U.S.: Comparison with the European Union in a Circular Economy Perspective. J. Mater. Cycles Waste Manag. 2019, 21, 1449-1461. [CrossRef] 
12. Caterpillar Sustainability Group Building a Better World I Caterpillar 2020 Sustainability Report. Available online: https:/ / reports.caterpillar.com/sr/index.php?_ga=2.187985838.762753356.1632740953-1279608895.1632740953 (accessed on 24 September 2021).

13. Stahel, W.R. The Circular Economy. Nature 2016, 531, 435-438. [CrossRef] [PubMed]

14. Korhonen, J.; Honkasalo, A.; Seppälä, J. Circular Economy: The Concept and Its Limitations. Ecol. Econ. 2018, 143, 37-46. [CrossRef]

15. Lewandowski, M. Designing the Business Models for Circular Economy-Towards the Conceptual Framework. Sustainability 2016, 8, 43. [CrossRef]

16. Wijkman, A.; Skånberg, K. The Circular Economy and Benefits for Society; Club Rome: Winterthur, Switzerland, 2015.

17. MacArthur, E. Towards the Circular Economy: Opportunities for the Consumer Goods Sector; Ellen MacArthur Foundation: Cowes, UK, 2013.

18. Ijomah, W.L.; McMahon, C.A.; Hammond, G.P.; Newman, S.T. Development of Robust Design-for-Remanufacturing Guidelines to Further the Aims of Sustainable Development. Int. J. Prod. Res. 2007, 45, 4513-4536. [CrossRef]

19. Saavedra, Y.M.B.; Barquet, A.P.B.; Rozenfeld, H.; Forcellini, F.A.; Ometto, A.R. Remanufacturing in Brazil: Case Studies on the Automotive Sector. J. Clean. Prod. 2013, 53, 267-276. [CrossRef]

20. Hartwell, I.; Marco, J. Management of Intellectual Property Uncertainty in a Remanufacturing Strategy for Automotive Energy Storage Systems. J. Remanuf. 2016, 6. [CrossRef]

21. Stål, H.I.; Corvellec, H. A Decoupling Perspective on Circular Business Model Implementation: Illustrations from Swedish Apparel. J. Clean. Prod. 2018, 171, 630-643. [CrossRef]

22. Leppänen, T.; Mustonen, E.; Saarela, H.; Kuokkanen, M.; Tervonen, P. Productization of Industrial Side Streams into By-ProductsCase: Fiber Sludge from Pulp and Paper Industry. J. Open Innov. Technol. Mark. Complex. 2020, 6, 185. [CrossRef]

23. Hummels, D.; Ishii, J.; Yi, K.-M. The Nature and Growth of Vertical Specialization in World Trade. J. Int. Econ. 2001, 54, 75-96. [CrossRef]

24. Jauhari, W.A.; Pujawan, I.N.; Suef, M. A Closed-Loop Supply Chain Inventory Model with Stochastic Demand, Hybrid Production, Carbon Emissions, and Take-Back Incentives. J. Clean. Prod. 2021, 320, 128835. [CrossRef]

25. Chopra, S.; Sodhi, M.S. Supply-Chain Breakdown. MIT Sloan Manag. Rev. 2004, 46, 53-61.

26. Karagoz, S.; Aydin, N.; Simic, V. End-of-Life Vehicle Management: A Comprehensive Review. J. Mater. Cycles Waste Manag. 2019, 22, 416-442. [CrossRef]

27. Yin, R.K. Case Study Research: Design and Methods; SAGE: Thousand Oaks, CA, USA, 2009; Volume 5, ISBN 1412960991.

28. Fargnoli, M.; Costantino, F.; Tronci, M.; Bisillo, S. Ecological Profile of Industrial Products over the Environmental Compliance. Int. J. Sustain. Eng. 2013, 6, 117-130. [CrossRef] 